\title{
A CRIAÇÃO REFLEXIVA DO EROTISMO NA TESSITURA LÍRICA DE ADÉLIA PRADO
}

\section{THE REFLEXIVE CREATION OF EROTICISM IN THE LYRIC WRITTING OF ADÉLIA PRADO}

Amanda Ramalho de Freitas BRITO (UNEAL)
Hermano de França RODRIGUES (UFPB)

Tanto faz

Funeral ou festim,

Tudo é desejo

$\mathrm{O}$ que percute em mim.

Adélia Prado (Fibrilações)

Resumo: Este artigo analisa a construção metapoética (reflexividade) do erotismo em Adélia Prado, procurando investigar como o sagrado torna-se parte constitutiva do corpo-poema. Ideia discutida por meio da análise do texto Festa do corpo de Deus. Nossa leitura está fundamentada, principalmente, nas discussões teóricas de Bataille (2014), que pensa a construção erótica em seu aspecto de contemplação e meditação poética, como um mecanismo que situa o ser conscientemente no universo, uma vez que repercute a transgressão necessária à descontinuidade da vida.

Palavras-chave: Erotismo. Poesia. Reflexividade.

\begin{abstract}
This article analyzes the metapoetic construction (reflexivity) of the eroticism in Adélia Prado, with the aim of investigating how the sacred becomes a constitutive part of the body-poem. This idea was discussed through the analysis of the text Festa do corpo de Deus. Our reading is mainly based on the theoretical discussions of Bataille (2014), who thinks the erotic construction in its aspect of contemplation and poetic meditation, as a mechanism that locates the being consciously in the universe, since it makes known the necessary transgression to the discontinuity of the life.
\end{abstract}

Keywords: Eroticism. Poetry. Reflexivity.

\section{O texto erótico: corpo-poema em Adélia Prado}

Partindo da premissa cambiante que envolve as discussões em torno do erotismo, procuramos propor uma leitura crítica não apenas do conceito filosófico de Eros, mas de como ele é construído no texto literário, adquirindo formalmente um caráter de representação. Conforme destaca Durigan (1985, p. 8), “o erotismo não imita a sexualidade, é sua metáfora. O texto erótico é a representação textual dessa metáfora”. Esse mecanismo metafórico do erotismo expande o nosso universo de compreensão da própria vida, na medida em que nos distingue da 
sexualidade animal, desprovida, a princípio, de sistemas de símbolos socialmente convencionados.

Dentro dessa perspectiva, entendemos símbolo como um elemento que estabelece relações com um determinado objeto para sugerir um significado ${ }^{1}$, sendo assim, caro aos sistemas de representação, assimilando, sobretudo a metáfora, que por meio da transferência gera uma imagem, um conceito novo e atualizado para a vida artisticamente incorporada.

Bataille (2014) compreende a práxis do erótico por via de um sistema semelhante ao da literatura, por meio da experiência mimetizada. Para o autor o erotismo se equivale à contemplação poética, uma vez que reitera a vida a partir de uma reelaboração de sentidos. Assim, "os homens fizeram de sua atividade sexual uma atividade erótica," (BATAILLE, 2014, p. 35), o que quer dizer que atribuíram sentido ao sexo para além da reprodução natural. Por isso, compreendemos com mais profundidade as molduras de Eros quando as investigamos no texto, que nesse caso seria o texto erótico. Para Antelo (2014, p. 21), o texto torna-se erótico justamente por meio do conceito de significância, do sentido produzido sensualmente. A criação sensual de um texto sugere, sobretudo, o seu aspecto sincrônico, tecendo ângulos e enquadramentos em torno do objeto erótico. Na poética de Adélia Prado, o Eros é, normalmente, sugerido por meio da unificação entre o corpo e o espírito ou entre o corpo $\left(\right.$ profano $\left.^{2}\right)$ e Deus (sagrado), assumindo assim o seu próprio módulo lírico. Ideia apreendida, por exemplo, no poema "Sagração", cujo título indica o processo de sagração do corpo, remontando a sagração do próprio erotismo, suscitada pela sensualização da linguagem, como observamos nos versos a seguir:

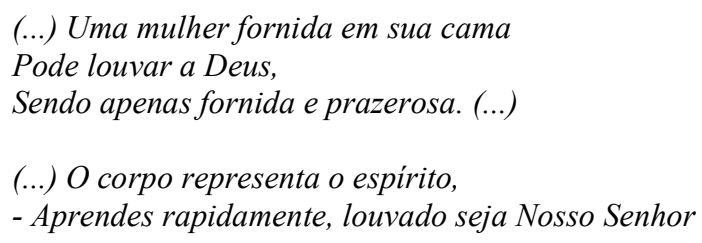

[Jesus Cristo! (...).

A sensualidade dos signos, que chamaremos aqui de nudez das palavras, poema-corpo, pois simboliza a carne e os desejos humanos de maneira substancial, revelando a transgressão

1 Essa perspectiva em torno da noção de símbolo é considerada por Charles S. Peirce no livro Semiótica, ao discutir as relações admitidas por um signo.

2 Etimologicamente a palavra profano significa fora (pro) do templo (fanum), e faz referência ao teatro popular desenvolvido no século $\mathrm{XV}$, que diferentemente do teatro religioso do século XII, não realizava mais suas peças no interior das igrejas. Desse modo, profano passou a exprimir tudo aquilo que havia perdido o seu valor sagrado. Por isso, utilizamos o termo para expressar a dessacralização do corpo expressada pelo cristianismo, e reconfigurada na poesia adeliana através da unificação. 
da vergonha do desejo e de palavras supostamente obscenas justamente por representar esse desejo como se traduz em outros poemas: cu (Objeto de amor); pelos púbicos (Entrevista); sexo (Trottoir), reivindicando o caráter divino, panteísta da matéria. Com efeito, esses signos obscenos revestem o sentido metafórico do corpo erótico sacralizado na poética adeliana, na qual o corpo da mulher é colocado na mesma esfera do divino, do rito, e consequentemente, da criação - o corpo é a criação, devido ao seu traço sui generis de parte integrante do cosmos. Esse significado, aliás, é reencontrado na acepção filosófica de Alberto Caeiro, em $H a ́$ metafísica bastante em não pensar em nada: o eu-lírico esboça um Deus materializado, sugerido pelas flores, árvores, montes, entre outros elementos da vida. A cosmovisão do panteísmo, como um dos sentidos para o erotismo na lírica de Adélia Prado, é proposta pela busca da união através de um Deus identificado com o próprio corpo humano.

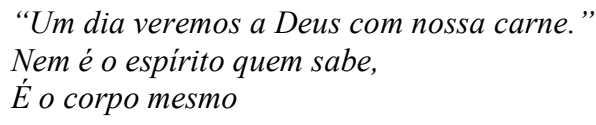

O verbo lírico adeliano acessa o sagrado pela união estabelecida com todos os elementos participativos da criação, inclusive, o sexo meditado, simbolizado pelos signos dos interditos. Em sentido contrário a dessacralização feita pelo cristianismo, que acessa a construção do erótico como recusa à compreensão e conexão com o divino. Castello Branco (1992) assinala, justamente, que o aspecto fundamental do mito de Eros é a união:

\begin{abstract}
A ideia de união não se restringe aqui apenas à noção corriqueira de união sexual ou amorosa, que se efetua entre dois seres, mas se estende à ideia de conexão implícita na palavra religare (da qual deriva religião) e que atinge outras esferas: a conexão (ou re-união) com a origem da vida (e com o fim, a morte), a conexão com o cosmo (ou com Deus para os religiosos), que produziriam sensações fugazes, mas intensas, de completude e de totalidade. (BRANCO, 1994, p. 66).
\end{abstract}

A conexão com o divino se confunde ainda com o próprio ser da poesia. Essa consideração focaliza ainda a travessia da reflexividade como um projeto estético, que relaciona Deus à criação poética. Por certo, a poesia de Adélia assimila o cristianismo, mas o faz, por sua vez, de uma maneira dialética: questionando e ressignificando a construção idiossincrática do divino. Por essa óptica, a relação entre Deus-poesia-erotismo se equivale à própria consciência da condição de representação da arte. E esta consiste no que Stam (2008) definiu como reflexividade.

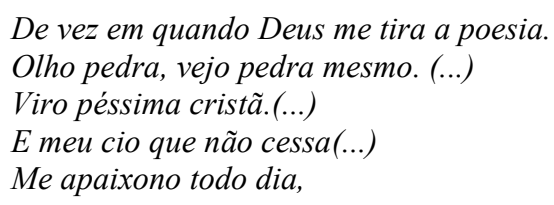


Escrevo cartas horriveis, cheias de espasmos,

Como se tivesse um piano e olheiras,

Como se chamasse Ana da Cruz. (...).

Sem os trevos no jardim

Não sei se escreveria esta escritura,

Ninguém sabe o que é um dom.

No poema Paixão, do qual retiro alguns versos ilustrativos, o movimento Deus-poesiaerotismo entabula metaforicamente o percurso da paixão de cristo com a paixão da voz lírica feminina adeliana, contorcendo-se com o pathos da procura da poesia, extraída de um cotidiano contemplado, desvelando-se de maneira divina, posto que, foi meditado, reinventado participando da mesma forma da criação (Deus-Poesia). Dessa maneira, o cotidiano desinteressado participa do sagrado, e o evangelho torna-se a criação lírica: se "Deus me tira a poesia/ viro péssima cristã”. E assim, Ana é como Jesus na cruz e o dom (a construção estética), a personificação de Deus. Efetivamente, A poesia, a salvação e a vida. As formas eróticas que tomam a poesia de Adélia Prado perpassam todo o projeto lírico da autora, anunciado em Modo Poético como próprio percurso de interiorização do eu-lírico: “é em sexo, morte e Deus/que eu penso invariavelmente todo dia." Tais apontamentos criam um quadro de reflexividade em que comumente os temas de Eros são associados à própria natureza da poesia, associando, em um mecanismo de continuidade, o homem e a arte, conteúdo e forma.

A configuração do erotismo se dá como forma afirmativa do desejo da mulher, da presença do feminino com voz e corpo em uma sociedade tendenciosamente fálica, que recusa doutrinalmente o desejo voluptuoso da mulher. Criticamente falando, a repressão feminina simboliza uma resistência, um medo ao gênero que revive através da reprodução sexual um estado estrito de reencontro total com a origem. Para melhor compreendermos essa questão, nos embasamos no conceito de erotismo reverberado por Bataille (2014). Para escritor, o erotismo é uma forma de continuidade simbólica para uma vida humana fatalmente descontínua, ou seja, finda, transitória. O misticismo, a arte e o erotismo repercutem a continuidade da vida. No caso do erotismo, a continuidade se dá em dois níveis de ocorrência: pelo amor, cujo sentimento de permanência é estabelecido na conjunção com o outro (o sexo meditado) e pela reprodução sexual, em que a vida gerada intrauterinamente funda a conexão perene. Partindo, desses pressupostos, a mulher é o ser consciente que mais se aproxima da totalização, da continuidade da vida e da criação, sendo, portanto, reprimida justamente por representar a totalidade.

Por meio do sexo "os corpos se abrem à continuidade através desses canais secretos que nos dão o sentimento de obscenidade" (BATAILLE, 2014, p. 41). E a obscenidade perturba a 
ordem natural dos corpos e da vida, criando uma consciência singular para o corpo e para vida. É por esse motivo que o cristianismo verbera os objetos obscenos, considerando-os configurações do pecado. Inversamente, a lírica adeliana reafirma esses objetos como sagrados (de tal modo como é representado em Objeto de Amor), reiterando os três níveis de continuidade da vida: Deus-poesia-erotismo. Com efeito, em Licença Poética, primeiro poema, do primeiro livro da autora (Bagagem), o eu-lírico traceja o motivo de sua lírica: "mas o que sinto escrevo. Cumpro a sina./ Inauguro linhagens.”.

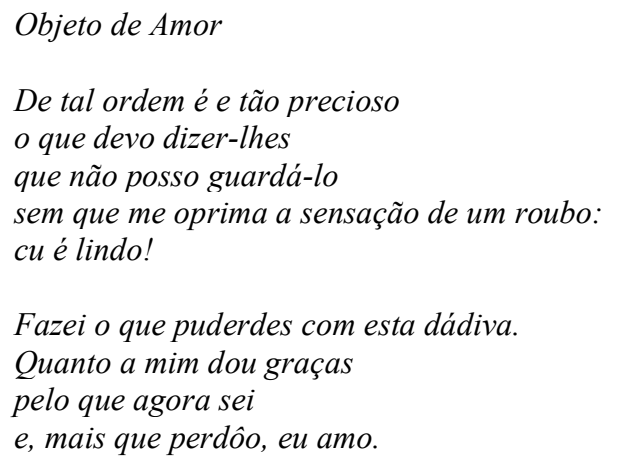

Ao dar voz poética aos objetos da antilírica, ela reafirma as preocupações da literatura contemporânea, que influenciada pelas estéticas vanguardistas do século XX, busca o lugar do não-lugar, do heterogêneo, e cujos textos verberam uma realidade em si, "buscando os processos que visam a atingir e a explorar as camadas materiais do significante" (BOSI, 2011, p.476). Tal processo é ratificado por meio da experimentação verbal, que procura atribuir sentido diferente a palavra-imagem, como aconteceu com os poemas de Augusto de Campos. No caso de Adélia Prado, a experimentação verbal se deu por meio da reflexividade (o poema é próprio leitmotiv: Licença poética; Paixão; Outros nomes de poesia), da criação palimpsesta (intertextualidade e diálogos com outras vozes: Poema com observâncias no totalmente perplexas de Guimarães Rosa; O antigo e novo testamento) e da configuração poética de signos antilíricos (Entrevista; Objeto de Amor; Sesta). Esses três traços estilísticos reforça a moldura estética do seu erotismo, dando corpo voluptuoso à poesia. Como expressou Manuel Bandeira (2012, p.27), em seu Itinerário de Pasárgada: “a poesia está em tudo - tanto nos amores como nos chinelos, tanto nas coisas lógicas como nas disparatadas.". A autora de Bagagem e de Terra de Santa Cruz, "funda linhagens" ao pôr em relevo a presença e os desejos da mulher, em uma cadência que une matéria e espírito, profano e sagrado. "Adélia supera a feminização do universo pela feminização temática" (CESAR, 1999, p. 230), o que fica evidente em Licença Poética e em Paixão. 
Essas considerações críticas em torno do objeto erótico no texto adeliano por meio da forma de representação reflexiva nos permite pensar o erotismo como um processo equivale ao da criação literária. Quando Bataille (2014) discute sobre o erotismo como uma das formas externas (as outras seriam a crença em Deus e a arte) de transgressão da morte por meio da ressignificação da realidade, não estaria acrescentando ao erotismo o caráter de representação? Doando à esfera psicanalítica e filosófica do conceito um caráter literário? Ideia, a propósito, sugerida pelo autor ao problematizar o conceito como mecanismo simbólico que se opõe à utilidade das coisas, nos dando uma compreensão em profundidade de nós mesmos: "o erotismo é o desequilíbrio em que o próprio ser se coloca em questão, conscientemente." (BATAILLE, 2014, p.55).

Essa abordagem alude, nada obstante, àquilo que Candido (1995) chama de função humanizadora da literatura, quer dizer, propiciar o refinamento das emoções do sujeito por meio do jogo dialético esboçado por cada texto literário, pondo em relevo uma consciência macroestrutural, da qual o indivíduo participa enquanto leitor. Assim, o erotismo e a literatura compartilham da mesma função: inquietar e perturbar o interlocutor. Prontamente, o erotismo na literatura tem a função de revelar uma consciência, de questionar a realidade. No poema Objeto de Amor, o eu-lírico controverte os padrões do conceito de beleza em torno do corpo, evidenciando o objeto obsceno de contemplação: "o cu".

A transgressão (apresentada também pelo questionamento de uma realidade meditada) é outra mola propulsora de intersecção entre o ser da literatura e o ser erótico, porque subverte, mesmo que simbolicamente, a condição efêmera da existência. E cria uma possibilidade de continuidade para o ser em descontinuidade. No erotismo "o que está sempre em questão é a substituição do isolamento do ser, de sua descontinuidade, por um sentimento de continuidade profunda.” (BATAILLE, 2014, p.39). A linguagem poética cria esse sentimento de continuidade profunda, pois como aponta Schopenhauer (1989): a arte afirma a possibilidade de uma existência infinda. Por isso, o tempo da poesia é o tempo do presente, da linguagem “cumpre-se, no poema, um tempo imanente à palavra, descondicionado ao ritmo do calendário, da duração interior e do mito.” (MOISES, 1989, p. 150). Daí a necessidade da arte, do erotismo como forma de transgressão e permanência.

Do erotismo na literatura é possível afirmar que é uma das formas de representação que participa do processo criativo de metaforização do mundo. Vendo-o dentro da poesia de Adélia Prado, ele potencializa o caráter reflexivo da sua linguagem, que como tema evidencia a busca por uma natureza indissociável, prolongada simbolicamente. E por esse viés, compreendemos 
o texto erótico como processo verossímil, representativo do sexo meditado na linguagem literária, pensado enquanto forma que se estabelece a partir do contexto e da proposta estética do autor (a). No conto Obscenidades para uma dona de casa (Ignácio de Loyola Brandão), por exemplo, a representação sexual é uma fantasia criada, através de cartas obscenas, pela personagem para transgredir a condição de tédio existencial, incidida sobre a mulher esgotada de sua função ornamental de dona de casa em uma rotina repetitiva, organizada pelo trabalho em uma sociedade fundamentalmente fálica. A representação do erotismo surge como possibilidade de transgressão e de elevação do desejo reprimido, da condição erótica do próprio sexo feminino. No texto adeliano, o erótico é simbolizado pela sacralização do corpo como pulsão da vida e do próprio Deus, tornando-o humanizado - o criador como parte da criatura, é um salmo lírico, no qual a poesia é um cântico de louvor: "Tudo que existe louvará./ Quem tocar vai louvar,/ quem cantar vai louvar,/ o que pegar a ponta de sua saia/ e fizer uma pirueta, vai louvar." (Um Salmo).

\section{Fibrilações líricas: Uma leitura de $A$ festa do corpo de Deus}

A festa do corpo de Deus é um texto de Adélia Prado, ao qual chamamos, em nossa análise, de corpo-poema, por refletir uma proposta estética que pensa o poema através das fibrilações do corpo, em outras palavras, o desejo e as pulsões da carne liricamente expostas em uma moldura plástica, que nos coaduna com a vida, experimentando-a em seu suplício sagrado. Inserido no terceiro livro da autora (no percurso da Catequese), Terra de Santa Cruz. Esse título faz referência ao nome dado ao Brasil, quando encontrado pelos portugueses. Esse viés da terra encontrada aponta um sentido interessante para a obra da autora: a descoberta de um simulacro poético, neste caso de uma voz feminina que inaugura "linhagens", desvelando o cotidiano pela via crucis do corpo.

O livro é segmentado em três percursos líricos: Território, Catequese e Sagração. Essa divisão indicia a travessia religiosa da póiesis adeliana, meditada como se fosse o próprio evangelho cristão. A partir de um panorama crítico: o Território simboliza o desbravamento lírico adeliano (a territorialização de um estilo); a Catequese, o evangelho segundo o corpopoema e a Sagração, a divinização, o ato sagrado da poesia, que nos faz experenciar o mundo.

É por meio da intersecção desses três caminhos que o erotismo é significado em $A$ festa do corpo de Deus. Como podemos apreender, os elementos formais evidenciam conscientemente a própria poesia. De acordo com Stam (2008, p 31), "ao chamar a atenção para a meditação Revista Graphos, vol. 19, n 2, 2017 | UFPB/PPGL | ISSN 1516-1536 
artística, os textos reflexivos subvertem o pressuposto de que a arte pode ser um meio transparente de comunicação, uma janela para o mundo." Nesse caso, a construção reflexiva do erotismo é uma maneira de subverter o sexo olhado de fora, da janela da das ideologias. Por meio da reflexividade, o erotismo é mostrado de dentro para fora, como podemos observar nos versos abaixo:

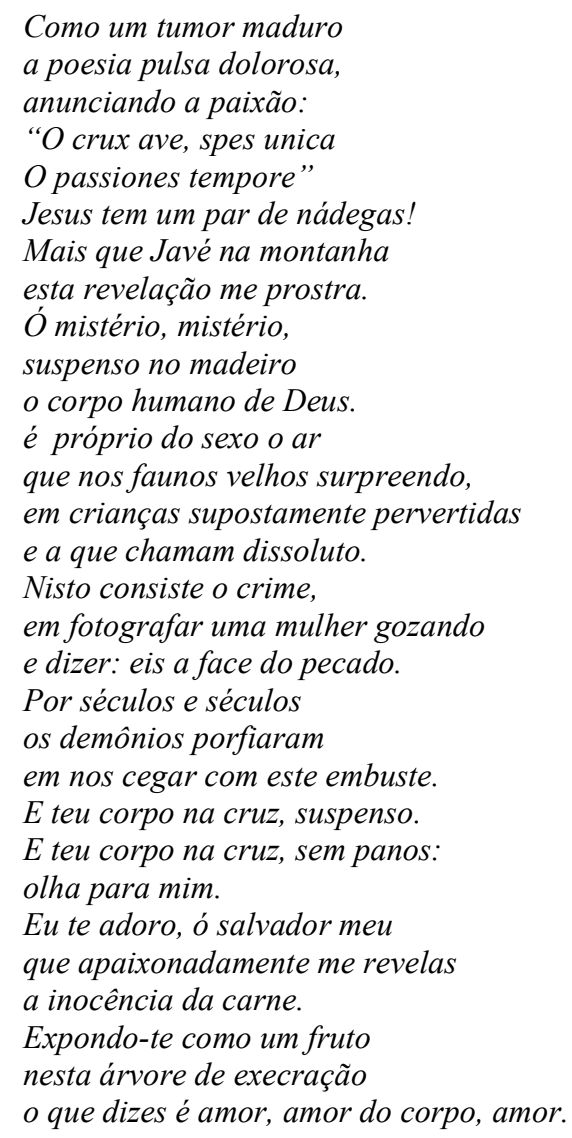

No domínio da reflexividade, com a qual apreendemos $A$ festa do corpo de Deus, o erotismo se revela por meio do diálogo metafórico com o discurso poético e a com a paixão de Cristo, melhor dizendo, a unificação entre poesia, corpo e cristo é feita pela configuração de um tema: o sofrimento. A poesia é colocada nos três primeiros versos como a paixão e, anuncia a paixão de cristo e do corpo. O elemento sagrado é posto em meditação como forma de questionar e negar o pecado do corpo. Com efeito, o pathos da via crucis é posto no mesmo plano da poesia, que "pulsa dolorosa", porque anuncia o crime: a dessacralização do sexo, do gozo feminino. Em face do interdito do pecado do corpo, o eu-lírico é atravessado pela revelação do corpo de Cristo, "o corpo humano de Deus”, símbolo da matéria, instaura uma epifania lírica, na qual a nudez do corpo divino: "revela a inocência da carne.". Esse movimento 
aproximativo assinala a natureza sublime do cotidiano. Como nos disse Alves em Oráculos de Adélia:

O poema traz o sublime para o cotidiano, o distante para o próximo. A visão do corpo de Cristo crucificado dá testemunho da corporeidade da vida. Não se trata, portanto, de uma visão que foge do sexo, do prazer, por considerá-lo pecado. A carne é inocente e a festa dos corpos pode ser um hino de louvor. (ALVES, 2007, p. 85)

A festa do corpo de Deus é uma metáfora subversiva para o corpo como interdito, como arquétipo do pecado. A negação do corpo é a negação do próprio Deus. A paixão faz referência, exatamente, à negação do corpo de Deus, Jesus, crucificado em decorrência de não se admitir a matéria para o espírito. Ideia sugerida no poema, que reitera Jesus como presença de um corpo sagrado no plano material: "Jesus tem um par de nádegas!”. O poema cria um jogo de inversão com os signos do cristianismo para afirmar "o amor do corpo", a essência divina na sexualidade, nos objetos da sensualidade, anunciando a beleza do que se configura como erótico. "Erotismo deixa entrever o avesso de uma fachada cuja aparência correta jamais é desmentida: no avesso, revelam-se sentimentos, partes do corpo e maneiras de ser de que comumente temos vergonha." (BATAILLE, 2014, p.133). Desse modo, a palavra poética adeliana torna-se desenvergonhada: "minhas fantasias eróticas, sei agora,/ eram fantasias do céu." (Trottoir).

\section{Referências}

ALVES, José Hélder Pinheiro. "Oráculos de Adélia". In: Revista de literatura brasileira Teresa. $\mathrm{N}^{\circ} 1,1^{\circ}$ semestre de 2000. São Paulo: Ed. 34, 2000, p. 233 - 236.

ANTELO, Raúl. "O lugar do erotismo". In: O erotismo. Belo Horizonte: Autêntica editora, 2014.

BANDEIRA, Manuel. Itinerário de Pasárgada. São Paulo: Global, 2012.

BATAILLE, Georges. O erotismo. Belo Horizonte: Autêntica Editora, 2014.

BOSI, Alfredo. O ser e o tempo da poesia. São Paulo: Companhia das Letras, 2000.

BRANCO, Lúcia Castello. "Erotismo”. In: $O$ que é: amor, erotismo, pornografia. São Paulo: Círculo do Livro, 1994.

CÂNDIDO, Antônio. “O direito à Literatura”. In: Vários escritos. São Paulo: Duas Cidades, 1995.

CESAR, Ana Cristina. Crítica e tradução. São Paulo: Ática, 1999.

DURIGAN, Jesus Antônio. Erotismo e Literatura. São Paulo: Ática, 1985.

MOISES, Massaud. A criação literária: poesia. 11. Ed - São Paulo: Cultrix, 1989.

Revista Graphos, vol. 19, n² 2, 2017 | UFPB/PPGL | ISSN 1516-1536 
PRADO, Adélia. Poesia Reunida. Rio de Janeiro: Record, 2006.

STAM, Robert. A literatura através do cinema: realismo, magia e a arte da adaptação. Belo Horizonte: Editora UFMG, 2008.

RECEBIDO EM 20-05-2017

APROVADO EM 03-06-2017 